\title{
Polyoma BK virus: an emerging opportunistic infectious agent of the human central nervous system
}

Authors

Rodrigo Lopes da Silva ${ }^{1}$

${ }^{1} \mathrm{MD}$, Hospital Santo António dos Capuchos CHLC, Lisbon, Portugal
Submitted on: $12 / 20 / 2010$ Approved on: 01/15/2011

Correspondence to: Rodrigo Lopes da Silva Hospital Santo António dos Capuchos - CHLC Alameda Santo António dos Capuchos , 1169-050 Lisbon, Portugal. ronolosi@gmail.com

I declare no conflict of interest.

\begin{abstract}
BK virus, a double-stranded DNA virus, is a member of the Polyomaviridae family which is known to infect humans. Clinical evidence of disease is mostly encountered in immunosuppressed individuals such as AIDS patients or those who undergo renal or bone marrow transplantation where complications associated with BKV infection manifest commonly as a polyomavirus nephropathy or hemorrhagic cystitis, respectively. Recent evidence suggests that in addition to the JC virus (the other member of the same family known to be strongly neurotropic and responsible for the progressive multifocal leukoencephalopathy), BK virus can infect and cause clinically relevant disease in the human central nervous system. In this mini-review, an analysis of the literature is made. A special focus is given to alert clinicians to the possibility of this association during the differential diagnosis of infections of the central nervous system in the immunocompromised host.
\end{abstract}

Keywords: BK virus; bone marrow transplantation; AIDS-related opportunistic infections.

[Braz J Infect Dis 2011;15(3):276-284] @Elsevier Editora Ltda.

\section{INTRODUCTION}

BK virus (BKV), also known as Polyomavirus hominis 1, was first isolated in 1971 from the urine of a renal transplant patient, initials B.K. $\mathrm{BKV}$ is a non-enveloped encapsulated circular double-stranded DNA virus that belongs to the Polyomaviridae family which includes other polyomaviruses that have been found to infect humans namely JC virus (JVC), simian virus 40 , KI virus, WU virus and Merkel cell polyomavirus (MCV). BKV is widely distributed in the human population. Primary asymptomatic infection usually occurs during childhood via the respiratory tract. Then, latent infection is established in renal epithelial cells and possibly other tissues (including brain, since BKV-DNA has been detected in the brain tissues from normal subjects) with most individuals having antibodies to BKV. Reactivation may subsequently occur in immunocompromised and healthy individuals, but may be more likely if there is an impairment of the immune function (patients with T-cell deficiencies). Clinical evidence of disease is rare and mostly encountered in patients in states of relative or absolute immunodeficiency, such as patients with AIDS or transplant recipients where BKV reactivation is associated with diverse entities such as polyomavirus nephropathy (PVN), a form of acute interstitial nephritis and the most frequent $\mathrm{BKV}$-associated disease after renal transplantation, or the hemorrhagic cystitis, a serious BKV-associated complication characterized by dysuria and varying degrees of hematuria that affects up to $10 \%$ of the bone marrow tran plant (BMT) patients. ${ }^{1-4} \mathrm{JCV}$, one of the other member of the Polyomaviridae family that causes human infection, is strongly associated with progressive multifocal leukoencephalopathy (PML), a demyelinating disease of the central nervous system (CNS). Until now, JCV was the only human polyomavirus known to have the ability to infect the CNS. Recently, however, an increasing body of evidence favors the possible neurotropism of BKV, since BKV DNA has been detected in the brain tissue and cerebrospinal fluid (CSF) of both immunocompetent and immunocompromised individuals (mostly adults) with or without neurological symptoms. ${ }^{5}$ 
BKV related CNS infection may often be overlooked and under-diagnosed in immunocompromised patients. Only a few cases of neurological disease associated with a possible or proved BKV infection have been reported so far, probably because the clinicians are generally unaware of this association. Herein, a synopsis of all the reported cases in the literature is made, including the clinical and imagiologic manifestations of BKV CNS infection, diagnosis, treatment and outcome.

Since it is an unknown, but emerging infectious disease of the CNS with the advent of more immunosuppressive therapy and procedures, and because in immunocompromised patients is mostly fatal, emphasis will be given to the importance of recognizing this entity and the urgent requirement of new treatments and antiviral drugs.

\section{$\mathrm{BKV}$ related CNS infection}

To date, since the first report of BKV associated neurological infection almost 20 years ago, only 24 cases have been described so far. ${ }^{6-23}$ Most of them occurred in patients with depression of their immune function (eight cases in AIDS patients; one case in a renal allograft recient; six cases in the context of hemato-oncological diseases under chemotherapy or bone marrow transplantation, and one case in a patient under longterm steroid therapy). However, eight cases were diagnosed in apparently healthy and immunocompetent individuals, with self-limited clinical manifestations (Table 1). Since clinical manifestations in healthy hosts are benign with rapid resolution of the symptomatology, attention will be given only to the cases of the immunocompromised individuals, mainly AIDS and transplant patients where the clinical picture is more complex and generally devastating, resulting in multi-organ failure and death.

As aforementioned, primary asymptomatic BKV infection usually occurs during childhood via the respiratory tract and after then latent infection is established in renal epithelial cells and possibly other tissues, including the brain, with reactivation in the immunodeficiency states. However, regarding the latent infection in this latter site, there are conflicting data, with some studies supporting a dormant BKV infection in the ependymal cells and astrocytes, ${ }^{5,24-28}$ while others fail to demonstrate that. ${ }^{29-32}$ Peripheral blood leukocytes were postulated as a site of latency. So, one argument against the concept of brain latency that explains the presence of $\mathrm{BK}$ virus in the brain of healthy people is that BK viral DNA detected by the PCR method may have been the result of contamination by peripheral blood leukocytes. Hence, further investigation in this area is needed to establish brain as a site of BKV latency. ${ }^{33-35}$ On the other hand, another study reported that endothelial cells support BKV replication in vitro, which raises the possibility that BKV may cross the endothelial barrier to disseminate from the periphery to its target organs via blood. ${ }^{36}$

\section{Neurological manifestations of BKV infection}

Individuals with CNS involvement by BKV infection, usually show signs and symptoms of acute encephalitis with some cases being accompanied by meningeal involvement. ${ }^{6-8,10-23}$ So far, only two cases presented an ophthalmologic disease manifested as an acute retinitis due to extension of the CNS BKV infection. ${ }^{8,9,13}$ The most common symptom is headache. Other signs of neurological impairment includes seizures, progressive mental deterioration, dysarthria, hallucinations, visual disturbances, and in one case paraplegia. In the pediatric group, irritability and lethargy were the preponderant manifestations. ${ }^{14}$ Of particular relevance is the fact that both cases of BKV retinitis occurred in AIDS patients. Thus, when the clinician evaluates this subset of immunocompromised patients with ophthalmologic symptoms, BKV must be included in the differential diagnosis, especially if concurrent CNS and urinary tract involvement by BKV infection is present. ${ }^{8,9,13}$

\section{Neuroimagiology of BKV infection}

Some microorganisms have a predilection for particular areas of the brain while others may affect multifocal areas of the cortex. For instance, herpes simplex type I has an affinity for the limbic system, cytomegalovirus favors the periventricular white matter, and Listeria monocytogenes is keen on the brain stem and cerebellum.

The CNS infection by BK virus is imagiologically characterized by a preferential involvement of the periventricular and pial surfaces of the brain parenchyma. In fact, magnetic resonance imaging of the cases of BKV meningoencephalitis shows areas of increased signal intensity of the periventricular white matter of brain while the cortex is generally spared. Meningeal contrast enhancement along with increased meningeal thickness also occurs when infection spread to meningis is present. Deep white matter of the cerebellum is generally spared while deep gray matter structures are compromised. ${ }^{6-8,10,11,18,19,21-23}$ There are two cases, one in a renal transplant recipient and another in a patient under long term steroids, suggestive of PML, but whose PCR for JCV was negative. ${ }^{16,17}$ Instead, BKV DNA of CSF and urine detected by PCR was positive. These cases illustrate and suggest that the etiology of some clinical diagnosis of PML might in fact be BKV and not JCV infection, so a high clinical index of suspicion is necessary in these particular cases.

\section{Diagnostic procedures/tests for suspected BKV infection}

The diagnosis of BKV meningitis/encephalitis has usually been established by PCR of the CSF, complemented or not by BKV PCR of the brain biopsy specimen. One report suggested that the presence of BKV with a dominant 


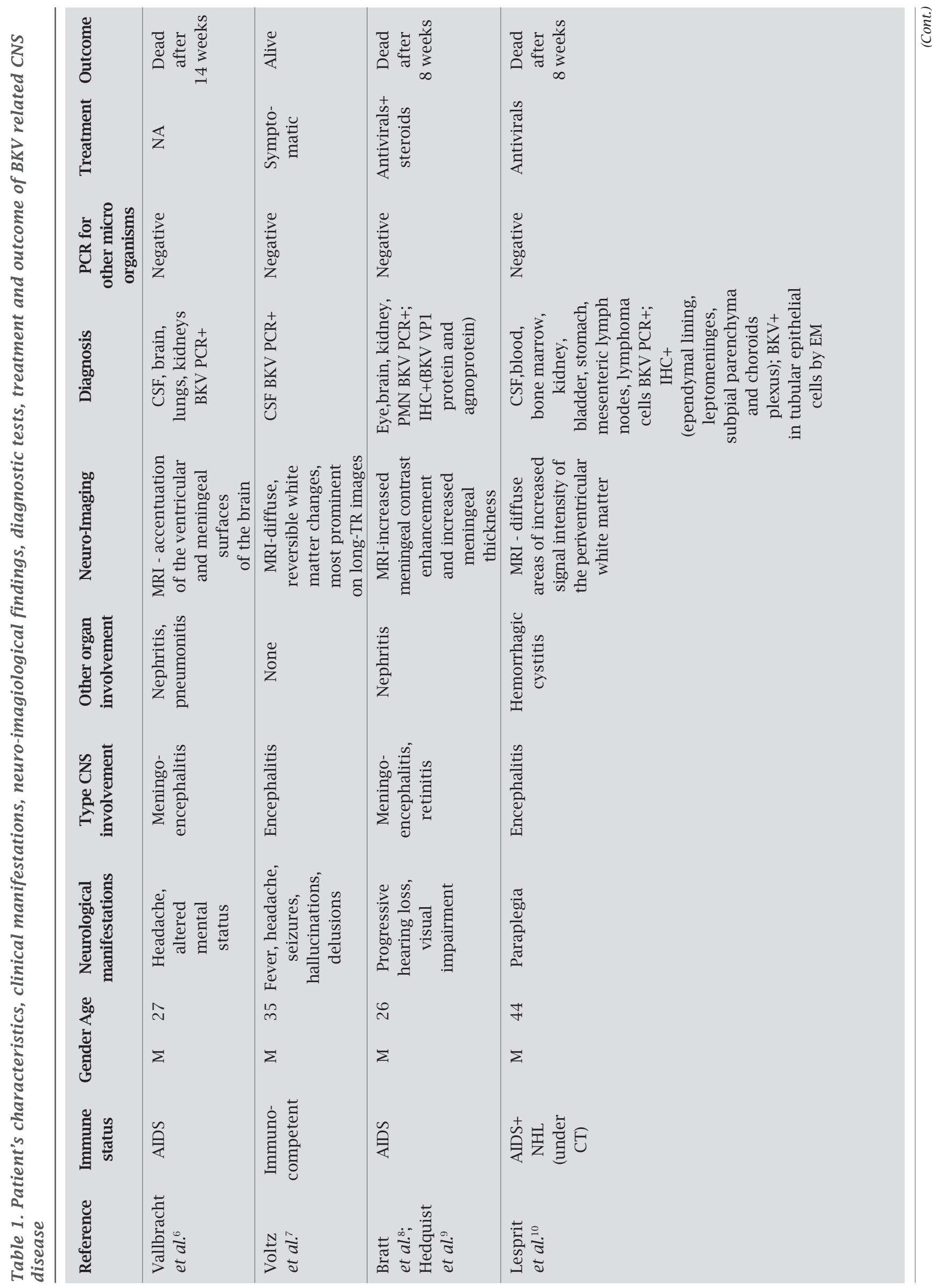




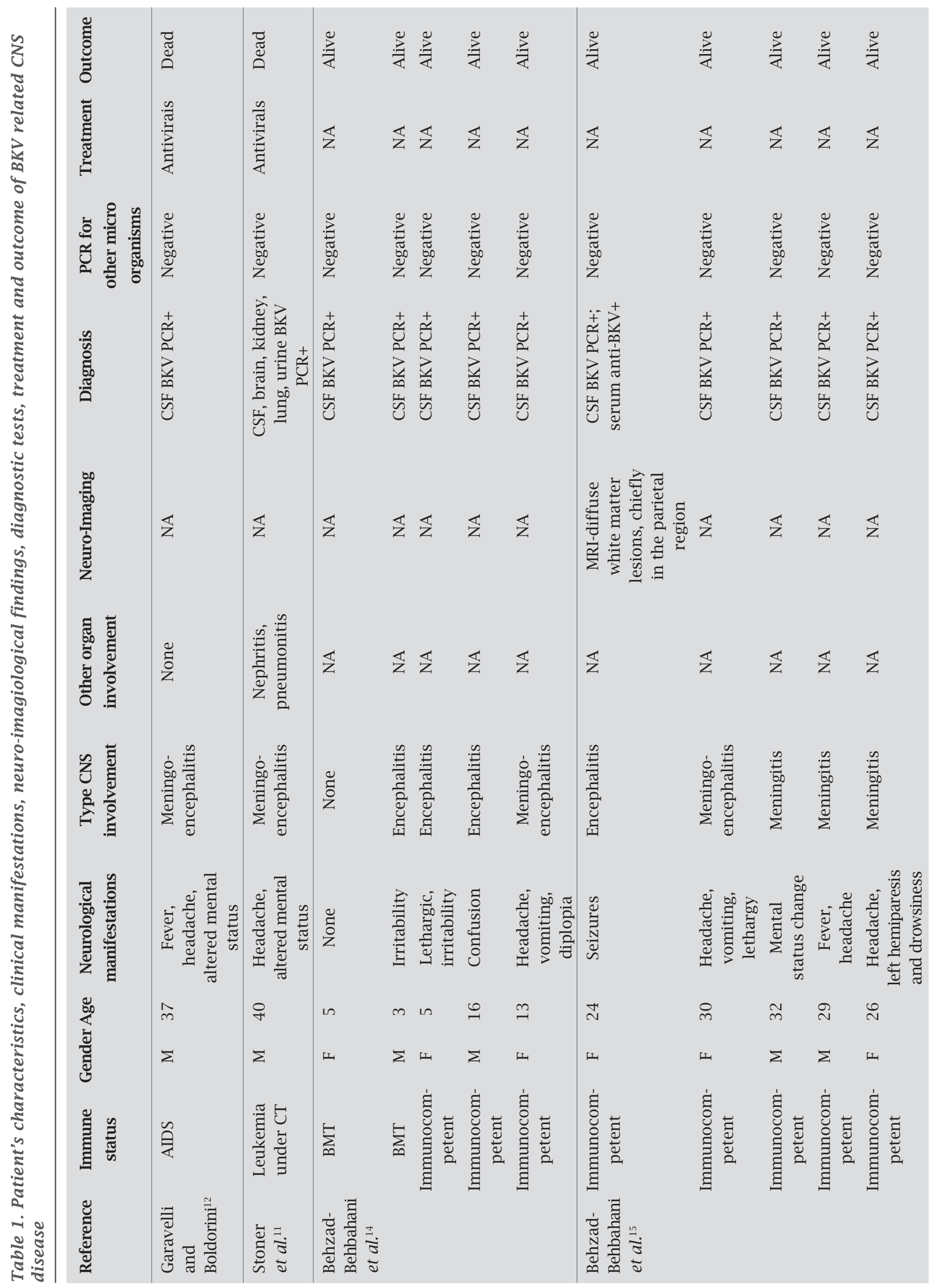




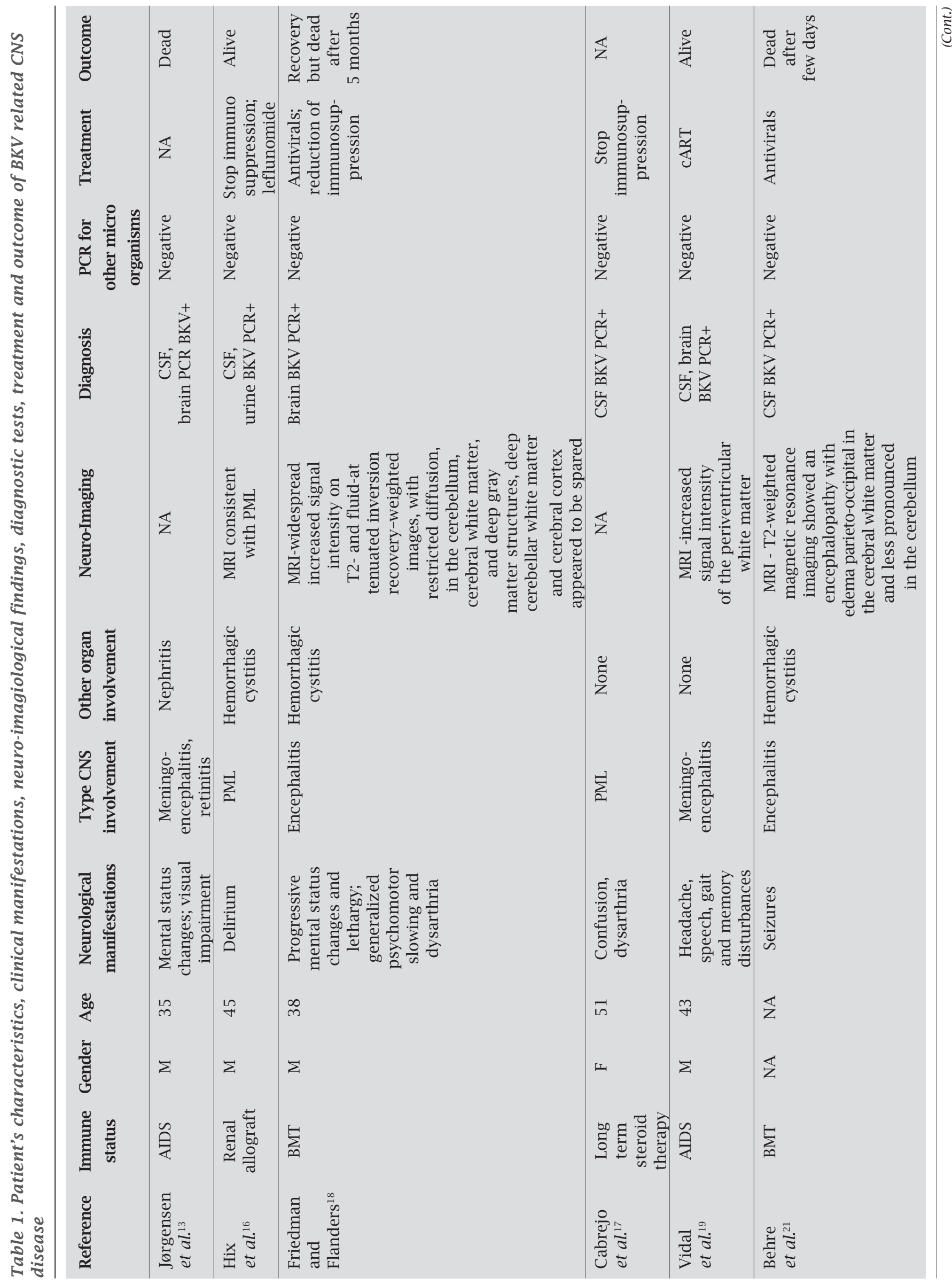




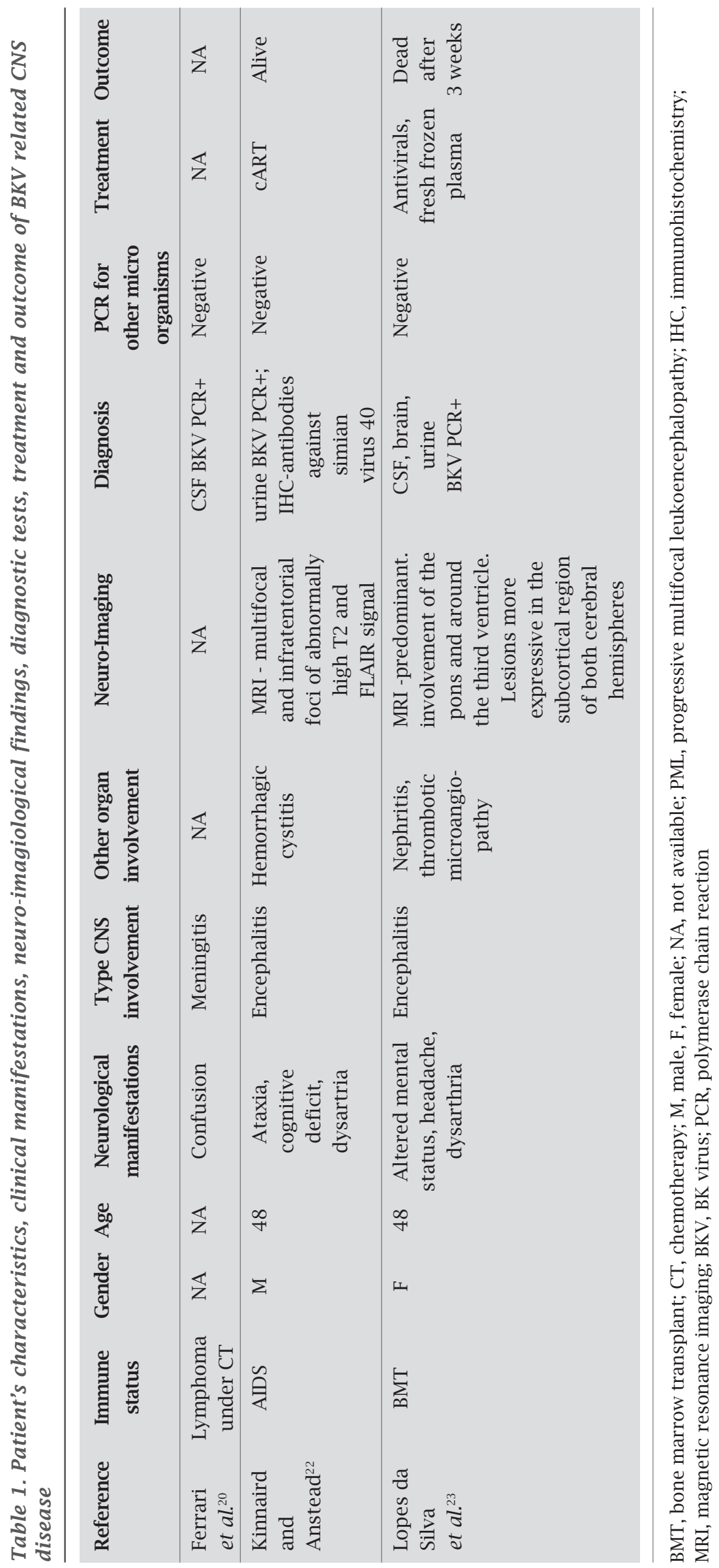


rearranged regulatory region in the CSF may be useful in the diagnosis of BKV meningoencephalitis secondary to BKV nephritis. ${ }^{11}$ In another report of an AIDS patient with nephritis, retinitis and meningoencephalitis due to BKV, investigators have discovered an undescribed reorganized non-coding control region (NCCR) variant of the virus in the CSF and CNS tissues, completely different from the variants detected in peripheral blood leukocytes and urine, which suggests that rearrangements in the NCCR of the virus led to the appearance of a $\mathrm{BKV}$ variant, which is much better adapted to the host cell machinery of the brain tissue and thus, more capable to initiate CNS infection in that particular patient. ${ }^{13}$ In two other reports, apart from PCR of CSF, brain tissue and other involved tissues, diagnosis has been reinforced by immunohistochemical staining for the two BKV proteins, the VP1 and the agnoprotein..$^{8-10}$

In most reports so far, the main limitation to conclude that BKV is the causative agent of the neurological disorders is the lack of demonstration of the virus in the brain tissue sample, either by immunohistochemistry or by in-situ hybridization. However, since most cases occur in AIDS and transplant recipients with multi-organ involvement by BKV infection, it is reasonable to assume that if a patient shows neurological symptoms without a positive serology and PCR for other pathogens (namely viral agents such as JCV, herpes simplex virus, cytomegalovirus, etc), while a positive PCR for BKV is present in the $\mathrm{CSF} / \mathrm{brain}$ tissue, it strongly favors the diagnosis of a $\mathrm{BKV}$ meningoencephalitis.

\section{Treatment}

Standardized antiviral management for BKV infection has not been established yet and is currently under investigation.

In AIDS patients with BKV encephalitis, immune reconstitution by combined antiretroviral therapy (cART) appears to improve the clinical status, but this needs further evaluation to be validated. ${ }^{19,22}$ In the transplant setting, reduction of immunosuppression is the cornerstone of therapy. However, the implications of this approach clearly has deleterious effects for the success of the transplant. Less immunosuppression combined with antiviral drugs may improve the outcome of these patients.

Cidofovir has shown some efficacy in the treatment of BKV-associated hemorrhagic cystitis, but can be nephrotoxic in renal transplant recipients. ${ }^{37-41}$ Leflunomide appears to be promising as an adjunctive treatment for BKV induced PVN in renal transplant patients. ${ }^{42,43}$

Use of quinolone antibiotics has also been advocated in the renal and BMT setting with some success. ${ }^{44-46}$ However, larger prospective studies are necessary to corroborate these results. New anti-viral drugs are being tested in clinical trials and some have completed the phase I trial in humans. ${ }^{47,48}$

\section{Outcome}

In healthy individuals, BKV CNS infection presents with mild and self-limited manifestations, easily handled by symptomatic approach. In the immunocompromised host, the outcome is often dismal with death occurring due to multi-organ failure or other complications. New antiviral drugs and treatment approaches are currently in progress.

\section{CONCLUSIONS}

BKV has recently emerged as an opportunistic CNS infectious agent in the immunocompromised host. Clinical evidence of CNS disease and detection of BKV DNA in the CSF and brain tissue of patients suspected to have either meningitis or encephalitis suggest that this virus has also some neurotropism.

BKV must be considered in the differential diagnosis of CNS disorders in AIDS and transplant patients, particularly those with a coexistent urologic disease and neurological decline.

\section{REFERENCES}

1. Reploeg MD, Storch GA, Clifford DB. BK virus: a clinical review. Clin Infect Dis. 2001; 33:191-202.

2. Hirsch HH.BK virus: opportunity makes a pathogen.Clin Infect Dis. 2005; 41:354-60.

3. Jiang M, Abend JR, Johnson SF, Imperiale MJ. The role of polyomaviruses in human disease. Virology 2009; 384:26673.

4. Boothpur R, Brennan DC. Human polyoma viruses and disease with emphasis on clinical BK and JC. J Clin Virol. 2010; 47:306-12.

5. Vago L, Cinque P, Sala E et al. JCV-DNA and BKV-DNA in the CNS tissue and CSF of AIDS patients and normal subjects.Study of 41 cases and review of the literature. J Acquir Immune Def Syndr Hum Retrovirol. 1996; 12:13946.

6. Vallbracht A, Löhler J, Gossmann J et al. Disseminated BK type polyomavirus infection in an AIDS patient associated with central nervous system disease. Am J Pathol. 1993; 143:29-39.

7. Voltz R, Jäger G, Seelos K, Fuhry L, Hohlfeld R. BK virus encephalitis in an immunocompetent patient. Arch Neurol. 1996; 53:101-3.

8. Bratt G, Hammarin AL, Grandien $M$ et al. BK virus as the cause of meningoencephalitis, retinitis and nephritis in a patient with AIDS. AIDS 1999; 13:1071-5.

9. Hedquist BG, Bratt G, Hammarin AL et al. Identification of BK virus in a patient with acquired immune deficiency syndrome and bilateral atypical retinitis.Ophthalmology 1999; 106:129-32.

10. Lesprit P, Chaline-Lehmann D, Authier FJ, Ponnelle T, Gray F, Levy Y. BK virus encephalitis in a patient with AIDS and lymphoma.AIDS 2001; 15:1196-9.

11. Stoner GL, Alappan R, Jobes DV, Ryschkewitsch CF, Landry ML. BK virus regulatory region rearrangements in brain and cerebrospinal fluid from a leukemia patient with 
tubulointerstitial nephritis and meningoencephalitis. Am J Kidney Dis. 2002; 39:1102-12.

12. Garavelli PL, Boldorini R. BK virus encephalitis in an HIV-seropositive patient. Preliminary data. Recenti Prog Med. 2002; 93:247.

13. Jørgensen GE, Hammarin AL, Bratt G, Grandien M, Flaegstad T, Johnsen JI. Identification of a unique BK virus variant in the CNS of a patient with AIDS.J Med Virol. 2003; 70:14-9.

14. Behzad-Behbahani A, Klapper PE, Vallely PJ, Cleator GM, Bonington A BKV DNA and JCV-DNA in CSF of patients with suspected meningitis or encephalitis.Infection 2003; 31:374-8.

15. Behzad-Behbahani A, Klapper PE, Vallely PJ, Cleator GM.BK virus DNA in CSF of immunocompetent and immunocompromised patients. Arch Dis Child 2003; 88:1745.

16. Hix JK, Braun WE, Isada CM. Delirium in a renal transplant recipient associated with BK virus in the cerebrospinal fluid. Transplantation 2004; 78:1407-8.

17. Cabrejo L, Diop M, Blohorn-Sense A, Mihout B. Progressive $\mathrm{BK}$ virus associated multifocal leukoencephalopathy in an immunocompromised patient treated with corticosteroids. Revue Neurologique 2005;161:326-30.

18. Friedman DP, Flanders AE. MR Imaging of BK virus encephalitis. AJNR Am J Neuroradiol. 2006; 27:1016-8.

19. Vidal JE, Fink MC, Cedeno-Laurent $\mathrm{F}$ et al. BK virus associated Meningoencephalitis in na AIDS patient treated with HAART. AIDS Res Therapy 2007; 4:13.

20. Ferrari A, Luppi M, Marasca R et al. BK virus infection and neurologic dysfunctions in a patient with lymphoma treated with chemotherapy and rituximab. Eur J Haematol. 2008; 81:244-5.

21. Behre G, Becker M, Christopeit M. BK virus encephalitis in an allogeneic hematopoietic stem cell recipient.Bone Marrow Transplant. 2008; 42:499.

22. Kinnaird AN, Anstead GM. Hemorrhagic cystitis and possible neurologic disease from $\mathrm{BK}$ virus infection in a patient with AIDS. Infection 2010; 38:124-7.

23. Lopes da Silva R, Ferreira I, Teixeira G et al. BK virus encephalitis with thrombotic microangiopathy in an allogeneic hematopoietic stem cell transplant recipient. Transpl Infect Dis. 2010;13:161-7.

24. Moret H, Guichard M, Matheron S et al. Virologic diagnosis of progressive multifocal leukoencephalopathy: detection of JC Virus DNA in cerebrospinal fluid and brain tissue of AIDS patients. J Clin Microbiol. 1993; 31:3310-3.

25. De Mattei M, Martini F, Tognon M et al. Polyomavirus latency and human tumors. J Infect Dis. 1994; 169:1175-6.

26. De Mattei M, Martini F, Corallini A et al. High incidence of $\mathrm{BK}$ virus large-T-antigen-coding sequences in normal human tissues and tumors of different histotypes. Int J Cancer 1995; 61:756-60.

27. Elsner C, Dorries K. Evidence of human polyomavirus BK and JC infection in normal brain tissue. Virology 1992; 191:72-80.

28. Dorries K. Molecular biology and pathogenesis of human polyomavirus infections. Dev Biol Stand. 1998; 94:71-9.

29. Chesters PM, Heritage J, McCance DJ. Persistence of DNA sequences of BK virus and JC virus in normal human tissues and in diseased tissues. J Infect Dis. 1983; 147:676-84.
30. White FA III, Ishaq M, Stoner GL et al. JC virus DNA is present in many human brain samples from patients without progressive multifocal leukoencephalopathy. J Virol. 1992; 66:5726-34.

31. FerranteP,Caldarelli-Stefano R, Omodeo-ZoriniEet al.PCR detection of JC virus DNA in brain tissue from patients with and without progressive multifocal leukoencephalopathy. J Med Virol. 1995; 47:219-25.

32. Perrons CJ, Fox JD, Lucas SB et al. Detection of polyomaviral DNA in clinical samples from immunocompromised patients: correlation with clinical disease. J Infect. 1996; 32:205-9.

33. Dorries K, Vogel E, Gunther S et al. Infection of human polyomaviruses JC and BK in peripheral blood leukocytes from immunocompetent individuals. Virology 1994; 198:59-70.

34. Sundsfjord A, Flaegstad T, Flo R et al. BK and JC viruses in human immunodeficiency virus type 1 -infected persons: prevalence, excretion, viremia, and viral regulatory regions. J Infect Dis. 1994; 169:485-90.

35. De Santis R, Azzi A. Duplex polymerase chain reaction for the simultaneous detection of the human polyomavirus BK and JC DNA. Mol Cell Probes 1996; 10:325-30.

36. Hanssen Rinaldo C, Hansen H, Traavik T. Human endothelial cells allow passage of an archetypal BK virus (BKV) strain--a tool for cultivation and functional studies of natural BKV strains. Arch Virol. 2005; 150:1449-58.

37. Siegert W. Treatment of BK virus-associated hemorrhagic cystitis and simultaneous CMV reactivation with cidofovir. Bone Marrow Transplant 2000; 26:347-50.

38. González-Fraile MI, Cañizo C, Caballero D et al. Cidofovir treatment of human polyomavirus-associated acute haemorrhagic cystitis. Transpl. Infect Dis. 2001; 3:44-46.

39. Barouch DH, Faquin WC, Chen Y, Koralnik IJ, Robbins GK, Davis BT. BK virus-associated hemorrhagic cystitis in a human immunodeficiency virus-infected patient. Clin Infect Dis. 2002; 35:326-9.

40. Ganguly N, Clough LA, Dubois LK et al. Low-dose cidofovir in the treatment of symptomatic BK virus infection in patients undergoing allogeneic hematopoietic stem cell transplantation: a retrospective analysis of an algorithmic approach. Transpl Infect Dis. 2010; 12:406-11.

41. Pallet N, Burgard M, Quamouss O et al. Cidofovir may be deleterious in BK virus-associated nephropathy. Transplantation 2010; 89:1542-4.

42. Wu JK, Harris MT. Use of leflunomide in the treatment of polyomavirus BK-associated nephropathy.Ann Pharmacother. 2008; 42:1679-85.

43. Araya CE, Garin EH, Neiberger RE, Dharnidharka VR. Leflunomide therapy for BK virus allograft nephropathy in pediatric and young adult kidney transplant recipients. Pediatr Transplant. 2010; 14:145-50.

44. Leung AY, Chan MT, Yuen KY et al. Ciprofloxacin decreased polyoma BK virus load in patients who underwent allogeneic hematopoietic stem cell transplantation. Clin Infect Dis. 2005; 40:528-37.

45. Koukoulaki M, Apostolou T, Hadjiconstantinou V, Drakopoulos S. Impact of prophylactic administration of ciprofloxacin on BK polyoma virus replication. Transpl Infect Dis. 2008; 10(6):449-51.

46. Gabardi S, Waikar SS, Martin S et al. Evaluation of fluoroquinolones for the prevention of BK viremia after renal transplantation. Clin J Am Soc Nephrol. 2010; 5:1298-304 
47. Randhawa PS, Farasati NA, Huang Y, Mapara MY, Shapiro R. Viral drug sensitivity testing using quantitative PCR: effect of tyrosine kinase inhibitors on polyomavirus BK replication. Am J Clin Pathol. 2010; 134:916-20.
48. Dropulic LK, Cohen JI. Update on new antivirals under development for the treatment of double-stranded DNA virus infections. Clin Pharmacol Ther. 2010; 88:610-9. 